\title{
Oculocutaneous albinism type 7
}

INSERM

\section{Source}

INSERM. (1999). Orphanet: an online rare disease and orphan drug data base.

Oculocutaneous albinism type 7. ORPHA:352745

Oculocutaneous albinism type 7 (OCA7), formerly called OCA5, is a form of oculocutaneous albinism (OCA; see this term) characterized by skin and hair hypopigmentation, nystagmus and iris transillumination. 